2001s-28

\title{
Complementarities in Innovation Policy
}

Pierre Mohnen, Lars-Hendrick Röller

Série Scientifique
Scientific Series

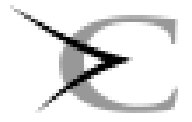

C I RANO

Ceatre imernaiversianire de ne

Montréal

Avril 2001 


\section{CIRANO}

Le CIRANO est un organisme sans but lucratif constitué en vertu de la Loi des compagnies du Québec. Le financement de son infrastructure et de ses activités de recherche provient des cotisations de ses organisationsmembres, d'une subvention d'infrastructure du ministère de la Recherche, de la Science et de la Technologie, de même que des subventions et mandats obtenus par ses équipes de recherche.

CIRANO is a private non-profit organization incorporated under the Québec Companies Act. Its infrastructure and research activities are funded through fees paid by member organizations, an infrastructure grant from the Ministère de la Recherche, de la Science et de la Technologie, and grants and research mandates obtained by its research teams.

\section{Les organisations-partenaires / The Partner Organizations}

•École des Hautes Études Commerciales

-École Polytechnique

-Université Concordia

-Université de Montréal

-Université du Québec à Montréal

-Université Laval

-Université McGill

-MEQ

-MRST

-Alcan inc.

-AXA Canada

-Banque du Canada

- Banque Laurentienne du Canada

-Banque Nationale du Canada

-Banque Royale du Canada

-Bell Québec

-Bombardier

-Bourse de Montréal

-Développement des ressources humaines Canada (DRHC)

-Fédération des caisses populaires Desjardins de Montréal et de l'Ouest-du-Québec

-Hydro-Québec

-Imasco

-Industrie Canada

-Pratt \& Whitney Canada Inc.

-Raymond Chabot Grant Thornton

-Ville de Montréal

(C) 2001 Pierre Mohnen et Lars-Hendrick Röller. Tous droits réservés. All rights reserved.

Reproduction partielle permise avec citation du document source, incluant la notice $\odot$.

Short sections may be quoted without explicit permission, if full credit, including $\odot$ notice, is given to the source.

Ce document est publié dans l'intention de rendre accessibles les résultats préliminaires

de la recherche effectuée au CIRANO, afin de susciter des échanges et des suggestions.

Les idées et les opinions émises sont sous l'unique responsabilité des auteurs, et ne représentent pas nécessairement les positions du CIRANO ou de ses partenaires.

This paper presents preliminary research carried out at CIRANO and aims at encouraging discussion and comment. The observations and viewpoints expressed are the sole responsibility of the authors. They do not necessarily represent positions of CIRANO or its partners. 


\title{
Complementarities in Innovation Policy ${ }^{*}$
}

\author{
Pierre Mohnen ${ }^{\dagger}$, Lars-Hendrick Röller ${ }^{\ddagger}$
}

\section{Résumé / Abstract}

Nous développons dans cet article un cadre qui permette de tester des complémentarités dans les politiques d'innovation à partir de données européennes sur les obstacles à l'innovation. Nous proposons un test discret de supermodularité en matière de politique à l'innovation qui repose sur un certain nombre de contraintes d'inégalité. Ce test s'appliquera à deux types de décision en innovation : innover ou non, et si oui, de combien? Nous constatons beaucoup de complémentarités au niveau des industries. Dans certaines industries la complémentarité touche l'ensemble des aspects pouvant donner lieu à des obstacles. Nous trouvons aussi que le manque de travailleurs spécialisés est complémentaire à tous les autres obstacles dans presque toutes les industries. Dans ce sens, nous résultats suggèrent que la détention de capital humain au niveau des entreprises est un élément essentiel dans une politique de l'innovation.

This paper develops a framework for testing discrete complementarities in innovation policy using European data on obstacles to innovation. We propose a discrete test of supermodularity in innovation policy leading to a number of inequality constraints. We apply our test to two types of innovation decisions: to innovate or not, and if so, by how much. We find that industries display a considerable amount of complementarity, with some industries being complementary across all obstacles. We also find that the lack of internal human capital (skilled personnel) is complementary to all the other obstacles in almost all industries. In this sense, our results suggest that internal human capital is key for any innovation policy, insofar that it is complementary to all the other factors that might hamper innovation activities.

Mots Clés : Innovation, supermodularité

Keywords: Innovation, supermodularity

\footnotetext{
* Corresponding Author: Pierre Mohnen, CIRANO, 2020 University Street, 25 ${ }^{\text {th }}$ floor, Montréal, Qc, Canada H3A 2A5 Tel.: (514) 985-4028 Fax: (514) 985-4039 email: mohnenp@cirano.qc.ca We would like to thank Dietmar Harhoff, Bernard Sinclair-Desgagné, and David Soskice for their detailed comments. We would also like to thank Susan Athey, Astrid Jung, and Jacques Mairesse, as well as participants of the WZB-CIRANO workshop on "Innovation and Supermodularity", June 15-17, Montréal. Julio Rosa provided competent research support. We acknowledge funding form the GAAC project on "Impediments to Innovation: A Complementarities Approach", by the research network 'Product Markets, Financial Markets and the Pace of Innovation in Europe' (Contract no. HPRN-CT-2000-00061) of the RTN Program of the European Commission, by the Social Science and Humanities Research Council of Canada strategic grant "Challenges and Opportunities of a Knowledge-Based Economy", and by Statistics Canada. All remaining errors are ours.

† Université du Québec à Montréal and CIRANO

$¥$ WZB, Humboldt University and INSEAD
} 


\section{Introduction}

The question as to whether policy variables are interrelated is important. In fact, this is one of the more central issues in policy analysis. Changing one policy variable may have no effect - or indeed an undesirable effect - if other policy variables are not changed at the same time. Understanding these interlinkages amongst choice variables may indeed be a prerequisite to successfully handle today's policy challenges. For example, what is the use of giving out R\&D tax incentives to stimulate $\mathrm{R} \& \mathrm{D}$, if the requisite $\mathrm{R} \& \mathrm{D}$ workforce is not available?

A prominent arena where such interlinkages are often cited is in the study of innovation. Innovation patterns display considerable variation across industries and countries. It is often argued that innovation is a complex outcome, influenced by many factors that are interrelated. More importantly, the interrelatedness of those factors is often described as one that is complementary, i.e. the factors act together and reinforce each other (Dosi, 1988). This paper provides a simple framework for empirically identifying and measuring complementarities in innovation policy.

A group of activities is complementary if doing more of any subset of them increases the returns from doing more of any subset of the remaining activities. In a standard (differentiable) framework, complementarity between a set of variables means that the marginal returns to one variable increases in the level of any other variable, or more formally that the cross-partial derivatives of some payoff function are positive. However, complementarity can also be present when the decision variables are discrete. The notion of complementarities per se requires only that some order relation be put on the objects under consideration. This observation has lead to the actual formalization of the concept within the mathematical theory of lattices, which started with the work of Arthur Veinott and Donald Topkis (see for instance, Topkis (1978)) ${ }^{\mathbf{1}}$.

The formalization of complementarities to discrete structures permits the analysis of such complex and discrete entities as organizational structures, institutions, and government policies. It provides a way to capture the intuitive ideas of synergies and systems effects, i.e. that "the whole is more than the sum of its parts." Furthermore, it constitutes the starting point for an understanding of the failure of piecemeal approaches to policy. For if the various elements of a given organization are complements, then adopting only some of the features of a better performing organization may not yield equivalent or better performance; it might actually worsen the current situation.

The study of complementarity has subsequently been introduced into economics. Paul Milgrom and John Roberts have considerably extended the initial work of Topkis and Veinott and pioneered its application to economics (see, for instance, Paul Milgrom and John Roberts

\footnotetext{
${ }^{1}$ Specifically, a lattice is a partially ordered set where each pair of elements $\{a, b\}$ has a least upper bound, noted $a \wedge b$, and a greatest lower bound, noted $a \vee b$. Two objects $a$ and $b$ are then called complementary if the corresponding payoff function $\Pi$ is supermodular, that is $11(a)-11(a \wedge b) \leq 11(a \vee b)-11(b)$.
} 
(1990)). For a recent reference on the theory of supermodularty and complementarity see Topkis $(1998)^{2}$.

An innovation system is often said to have discrete characteristics encompassing a set of institutions, laws, incentives, and customs. Most importantly, factors are said to create a set of complementarities, through which decision variables reinforce each other. A consequence of this is that piecemeal policy may not be successful, as one-dimensional policy prescriptions in isolation will not produce the desired outcomes.

This paper develops a framework for testing discrete complementarities in innovation policy. Our approach is based on governments choosing a set of parameters (policies) at the national level in order to maximize innovation activities. A trade-off for the government is introduced by assuming that policies have different effects on innovation activities at the industry level. For example, mandatory patenting might be a good policy in pharmaceuticals where it is easy to define a new product and customary for firms to patent, but it might be detrimental in other industries where secrecy is preferred to patenting as a means to appropriate innovation benefits. Another example might be tax credits. Handing out tax credits to promote R\&D and innovation will help profitable and well-established firms but will be useless and maybe even counterproductive for startup firms or loss-making enterprises (Eisner, Albert and Sullivan (1984)). Finally, a legal system clearly defining and defending property rights provides a reliable and congenial framework for growing firms, but too much regulation and concerns about establishing property rights might stand in the way of innovation diffusion.

Within this trade-off for policy decisions by government we like to ask whether policy decisions are complementary. If so, we would expect certain policy actions to occur together in order to maximize the impact on innovation activities. To address this question, we will assume that the impact of policy actions on the innovation activity in a given industry is identical across countries. In other words, staying with the above example, mandatory patenting is an innovation enhancing policy in pharmaceuticals in all countries. This assumption will lead to a similar tradeoff for all countries, which implies that the complementarities are industry specific ${ }^{3}$.

Even though the trade-off is the same for all countries, this does not imply that countries will all choose the same set of policies. Our approach will assume that there are country and industryspecific factors. For instance, countries or industries might differ because of their institutional endowments. According to North (1994, page 360):

"Given that these institutions are likely to be different across countries and industries, such as institutions, laws, incentives, customs, etc., they will translate into countryspecific and firm-specific heterogeneity, which in turn may lead to different outcomes."

${ }^{2}$ Another early contribution to economics is Vives (1990). There are also several empirical contributions to the study of complementarity, see for instance Ichniowski et al. (1997), Athey and Stern (1998), and Miravete and Pernias (2000).

${ }^{3}$ Alternatively, one could allow for the trade-off to vary across industries and countries. However, this will lead to a number of complications in the econometric specification. In this sense, our assumption of "global" complementarities at the industry level is more tractable. 
One of the key identification assumptions of our framework is that these institutional endowments are separable from the rest of the system. In other words, the complementarity of the objective function is independent of the endowments. Given this separability assumption, we are able to develop a conceptual framework within which we can test complementarities in innovation policies.

Using this framework we are able to specify a discrete test of supermodularity in innovation policy leading to a number of inequality constraints. Our test is based on directly estimating the objective function of the policy makers. In principle, testing for complementarity can be achieved by investigating whether the choice variables are correlated. An alternative approach is to test for complementarity in innovation policy by directly testing whether the objective function is supermodular. This is the approach taken in this paper.

We apply our test to a new data set on European firms. For two reasons, we like to differentiate between two types of innovation activities: the intensity of innovation, conditional on doing any innovation at all, and whether a firm does any innovation or not. The first reason for considering the two innovation activities explicitly is that we only observe innovation activities, conditional on doing any innovation at all. In other words, we have a censoring problem. In order to obtain consistent estimates of complementarity in innovation, we estimate the probability of being an innovator, which is then used to correct for the sample selection.

The second reason is that the complementarities may be rather different for the two types of innovation activities. Policy impacts as well as complementarity in policy may be rather different for the intensity of innovation, as compared to the likelihood of becoming an innovator.

Our results suggest that industries display a considerable amount of complementarity, with some industries being complementary across all obstacles. Generally, complementary in the intensity of innovation appears to be more pronounced than in the probability of becoming an innovator. This indicates that these two innovation processes, i.e. the intensity of innovation vs. the probability of becoming an innovator are subject to different constraints. This also implies that policies to remove obstacles to innovation may result in rather different effects, depending on whether they are designed to stimulate innovation by incumbents (i.e. the intensity of innovation, conditional on being an innovator) or to stimulate entry (i.e. increase the probability of becoming an innovator).

In terms of obstacles we find that the lack of internal human capital (skilled personal) is complementary with all the other obstacles in almost all industries. This is true for both the intensity of innovators as well as new innovators. It appears that internal human capital is key, insofar that it is complementary to all the other factors that might hamper innovation activities. In terms of innovation policy this finding of human capital complementarity suggests that measures directed at removing barriers to innovation may be more effective if those measures are also explicitly directed at increasing the level of internal human capital.

The paper is organized as follows. Section 2 develops the framework, while Section 3 defines supermodularity in innovation. Section 4 specifies the test and section 5 discusses the results. Section 6 concludes. 


\section{Innovation Policy}

We begin by assuming that innovation in each industry is affected by $K$ policy variables, which are taken by governments at the national level. We denote government actions in country $j$ by a vector $a_{j}=\left(a_{1 j}, a_{2 j}, \ldots, a_{K j}\right)$. Note that these actions are not industry-specific, and are set at the economy-wide level.

Innovation takes place at the industry level and is determined by the $K$ policy variables as well as country-specific and industry-specific exogenous factors denoted by a vector $\theta_{i j}$, such that $I_{i}\left(a_{j}, \theta_{i j}\right)$, where $i$ denotes the industry. The exogenous factors $\theta_{i j}$ represent institutions, history, customs, norms, technologies, etc. and are assumed to be separable from the government's actions. As we will see below, this allows us to consider the issue of complementarity in actions independently of the exogenous factors.

Another important assumption we are making is worth emphasizing early: the industry-level innovation function $I_{i}\left(a_{j}, \theta_{i j}\right)$ does not depend on the country (except for the institutional endowments $\theta_{i j}$ ). In other words, the effect of the governments actions does not depend on the country, only the industry. This implies that a particular industry's needs in terms of policies (for instance easy finance, flexible labor markets) are identical across all countries. This assumption is crucial insofar it will imply that complementarity in a particular industry exists either for all countries, or for no country ${ }^{4}$.

For conceptional purposes, one could think of a two-stage framework. In stage two, domestic firms in each industry maximize innovation given a particular policy. Stage one allows for the national governments to choose the innovation environment. The problem of the government is then to choose a set of "national parameters" $a_{j}=\left(a_{1 j}, a_{2 j}, \ldots, a_{K j}\right)$ that maximize innovation across all industries, i.e. $\max _{a} \sum_{i} I_{i}\left(a_{j}, \theta_{i j}\right)$. A trade-off is present whenever an action has opposite effects on innovation across industries. For example, an increase in $a_{1 j}$ may increase innovation in industry $i$, but decrease innovation in industry $i+1$. In other words, governments cannot create the optimal environment for each industry, as they set parameters at the national level. ${ }^{5}$

Given this environment we like to provide evidence on the existence of complementarity in government actions. In principle there are two levels at which complementarity could exist: (i) there could be complementarity at the economy-wide level (macro-complementarity), and/or (ii) there could be complementarity at the industry level (micro-complementarity). Testing macrocomplementarity would imply a test of whether innovation at the economy-wide level is complementary in government actions, i.e. whether $\sum I_{i}\left(a_{j}, \theta_{i j}\right)$ is supermodular in $a$.

Analogously, testing micro-complementarity would imply a test of whether innovation at the

\footnotetext{
${ }^{4}$ It is unclear as to why the trade-off would vary across countries, given that technologies and thus the constraints faced by firms should all work in the same direction across countries. For this reason, it appears more reasonable to base national differences on the exogenous variables rather than the trade-off within an industry.

5 For example Levin et al. (1987) show that patents are perceived as effective means of appropriability in Pharmaceuticals but not in most of the other industries.
} 
industry-wide level is complementary in government actions, i.e. whether $I_{i}\left(a_{j}, \theta_{i j}\right)$ is supermodular in $a$.

Lemma 2.6.1 from Topkis (1978) shows that the sum of supermodular functions defined on a lattice, is also supermodular. In our context this implies that whenever the innovation function for all the industries are supermodular, so is the entire country-level objective function. Including weights on the individual industry innovation functions does not change this result (see Lemma 2.6.1. in Topics (1978)). In other words, micro-level complementarity for all industries implies macro-level complementarity. The reverse is not true.

Testing for complementarity in innovation policies could, in principle, proceed by checking supermodularity of $I_{i}\left(a_{j}, \theta_{i j}\right)$, assuming that data on government actions are available. Unfortunately, the available data on innovation (see below) do not report government actions. Instead, we have measures of the obstacles to innovation. Assuming that the relationship between actions and obstacles is monotone, we can infer complementarity between actions by measuring complementarity between obstacles. In particular, monotonicity between actions and obstacles is likely to hold within an industry, which allows us to proxy actions with obstacles. Given that only obstacles are observable, and assuming that monotonicity between actions and obstacles holds at the industry-level, we proceed to measure complementarity in actions at the industry level only.

Let the industry-level innovation function be defined as follows,

$$
I_{i}\left(a_{j}, \theta_{i j}\right)=f_{i}\left(C_{1 i}\left(a_{1 j}\right), C_{2 i}\left(a_{2 j}\right), \ldots ., C_{k i}\left(a_{K j}\right), \theta_{i j}\right)
$$

where $C_{k i}$, where $k=1, \ldots, K$ are a number of innovation constraints faced by firms in industry $i$. These innovation constraints are in turn determined by the actions of the government in country $j^{6}{ }^{6}$ According to the above mentioned trade-off for the government an action may have opposite effects on obstacles across industries. For example, an increase in $a_{1 j}$ may increase the constraint $C_{1 i}$ in industry $i$, but decrease the constraint $C_{1, i+1}$ in industry $i+1$. In particular, we will assume that the effect of $a_{k j}$ on $C_{k i}\left(a_{k j}\right)$ is weakly monotone for each $k, j$, and $i$. In line with the above argument, we assume that $C$ depends only on the industry and the actions, not the country. This implies that the effect of an action on a constraint is the same across countries in a given industry, i.e. complementarity in a particular industry exists either for all countries, or for no country.

Given monotonicity at the industry level, we are able to measure complementarity in actions through data on obstacles. In other words, we can simplify [1] to,

$$
I\left(C_{i}, \theta_{i j}\right)=f\left(C_{1 i}, C_{2 i}, \ldots, C_{k i}, \theta_{i j}\right)
$$

and test whether [2] is supermodular in the obstacles. Given that we will measure complementarity in obstacles and that the effects of actions on obstacles are potentially very different across industries (this is indeed where the government's trade-off comes from), we are not able to link our results to precise policy measures. However, we are able to provide evidence on whether complementarity in policy actions exist.

\footnotetext{
${ }^{6}$ Note that [1] assumes that each action effects exactly one constraint.
} 


\section{Supermodularity of the Innovation Function}

Given the above framework, we can now define complementarity in innovation policy by checking whether the innovation function is supermodular in obstacles. Let the innovation function for industry $i$ be given by [2], where the obstacle set $C\left(C_{i} \in C\right)$ is a set of elements that form a lattice and the $\theta$ 's are exogenous parameter. We define complementarity of the innovation function as follows (see for example Milgrom and Roberts 1990, page 516).

Definition: Let $C_{i}^{\prime}$ and $C_{i}^{\prime \prime}$ be two elements in the obstacle set. Then the industry innovation function $I\left(C_{i}, \theta_{i j}\right)$ is supermodular if and only if $I\left(C_{i}^{\prime}, \theta_{i j}\right)+I\left(C_{i}^{\prime \prime}, \theta_{i j}\right) \leq I\left(C_{i}^{\prime} \vee C_{i}^{\prime \prime}, \theta_{i j}\right)+I\left(C_{i}^{\prime} \wedge C^{\prime \prime}, \theta_{i j}\right)$.

We will test this below.

\section{A Simple Example:}

A simple example might be useful for illustrative purposes. Suppose there are two binary decision variables, which implies that the set $C$ consists of four elements $C=\{\{00\},\{01\}\{10\},\{11\}\}$. For example, a country may adopt flexible labor markets and a market-based financial system (corresponding to $C_{i}^{1}=00$ ) or choose less flexible labor markets and less marketbased finance (corresponding to $C_{i}^{4}=\{11\}$ ), as well as the mixed cases. Define the ordering of the elements in the set $a$ as the component-wise order under the "max" operation, for example $C_{i}^{2} \vee C_{i}^{3}=(\max \{01\}, \max \{10\})=\{11\}=C_{i}^{4}$. This will produce the Hasse diagram below.

\section{Figure 1}

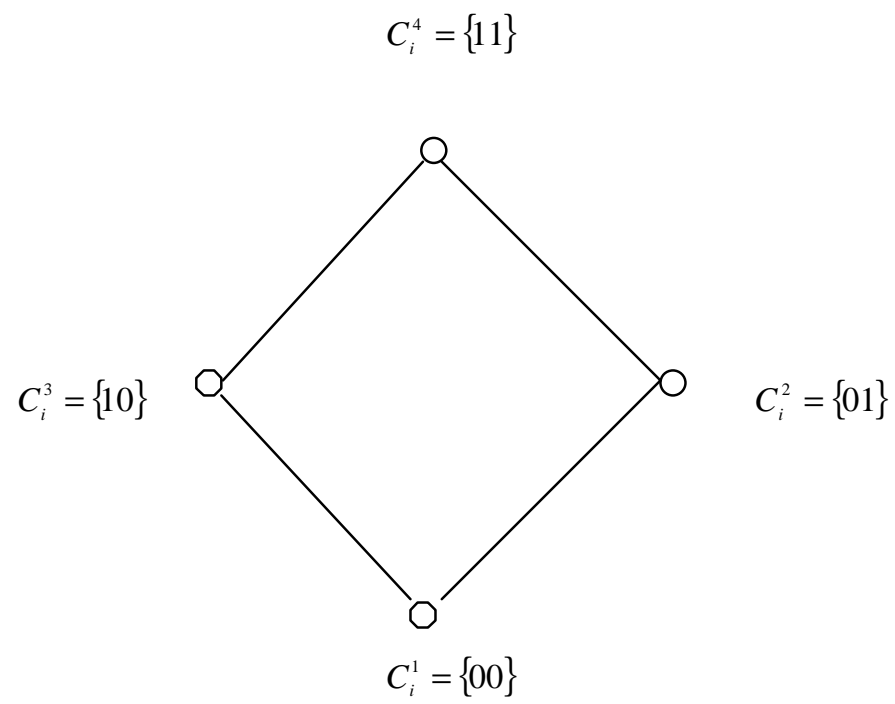


Using the above definition of supermodularity, several other useful results can be derived. For example, using properties of systems of complements relating to monotone comparative statics, it can be shown (see Milgrom and Shannon, 1994) that the comparative statics on the maximizers $C_{i}^{*}(\theta)$ are unambiguous, whenever $I\left(C_{i}, \theta_{i j}\right)$ is supermodular with respect to the lattice $C$. In other words, the set of choice variables in $C$ are complementary, moving up or down together in a systematic, coherent fashion, depending on the environmental parameter $\theta_{i j}$.

Another important result for the empirical implementation below is that it suffices to check pairwise complementarities in case there are more dimensions than two in the lattice (Topkis, 1978). In other words, a function is supermodular over all its arguments, if and only if all pairwise components satisfy the above definition.

As was mentioned above, (see Topkis (1978)) the sum of supermodular functions defined on a lattice is also supermodular. This implies that micro-level complementarity for all industries implies macro-level complementarity. The reverse is not true.

Given these properties of supermodularity, we now derive the constraints that need to be satisfied for the industry innovation function to be supermodular. Let the $K$ obstacles to innovation be binary, i.e. they take on the value of either 1 (high) or 0 (low). Define an element of the set $C$ $\left(C_{i} \in C\right)$ as a string of $K$ binary digits, where the individual binary components of each element of the set $C$ represent the obstacles to innovation. Thus, there are $2^{K}$ elements in $C$. In terms of our data set below we have chosen 4 obstacles, which implies that $K=4$. The elements in $C$ are therefore (0000), (0001), (0010),.....,(1111), a total of 16 elements. Define the ordering of the elements in the set $C$ as the component-wise order under the "max" operation (like in the above simple example). This implies that the set $C$ is a lattice. Finally, define the innovation function [2] over the set $C$.

Using the definition of supermodularity, and the fact that we only need to check pair-wise elements, it can be shown that the number of nontrivial ${ }^{7}$ inequality constraints implied by the definition of supermodularity is equal to $2^{(K-2)} \sum_{i=1}^{K-1} i$, where $K$ is the number of obstacles and $i=2$ (binary). Since $K=4$, we have a total of 24 nontrivial inequality constraints.

In particular, using the above definition of supermodularity we can write the 4 nontrivial inequality constraints for obstacle 1 and 2 to be complementary in innovation as,

$$
I(10 X X)+I(01 X X) \leq I(00 X X)+I(11 X X) \text {, where } X X=\{00,01,10,11\}
$$

Similarly, the 4 nontrivial inequalities necessary to hold for obstacles 1 and 3 to be complementary are,

$$
I(1 X 0 X)+I(0 X 1 X) \leq I(0 X 0 X)+I(1 X 1 X) \text {, where } X X=\{00,01,10,11\} .
$$

\footnotetext{
${ }^{7}$ The remaining constraints are equalities.
} 
The remaining 16 constraints corresponding to complementarity between obstacles 1 and 4, 2 and 3, 2 and 4, and 3 and 4 are analogous. Complementarity over all actions is given, whenever all the 24 inequality constraints are satisfied.

We next turn to the empirical analysis, which will test for complementarity by checking whether these constraints are accepted by our data on innovation.

\section{Empirical Implementation}

Testing for complementarity can be achieved by investigating, whether the choice variables are correlated (see for example Miravete and Pernias (2000)). For instance, within the context of our simple example above, if the two countries are located at $\{11\}$ and $\{01\}$, there is little evidence of complementarity. However, evidence of complementarity would be if one country is at $\{11\}$ and the other at $\{00\}$. One approach followed by Miravete and Pernias (2000) is to estimate the correlation in choice variables from the first-order conditions. Generally, this procedure requires observability of the choice variables, but not the objective.

An alternative approach is to test for complementarity in innovation policy by directly testing whether the objective function is supermodular, which requires that the objective is observable. This is the approach followed in this paper.

After a brief description of the data we will then turn to our test of complementarity.

\subsection{The CIS data}

In 1992, the statistical agency of the European Union - Eurostat - directed a coordinated effort to collect firm-level data on innovation in the EU member countries. The Community Innovation Survey (CIS 1) data were collected using a similar questionnaire and comparable sampling procedures. To date, there has been relatively little econometric analysis of this data set, but given the information it offers, it is ideally suited for tackling the research tasks described here.

The data set comprises individual firm data on some general characteristics of the firm (main industry of affiliation, sales, employment, export sales), various innovation measures, numerous perceptions of factors hampering or fostering innovation, and some economic impact measures of innovation. We use the CIS 1 survey data from four countries: Ireland, Denmark, Germany, and Italy. ${ }^{8}$ The data are made publicly available at a micro-aggregated level, i.e. continuous variables are averaged over three observations of consecutive rank within an industry. Non-aggregated individual responses can be used for empirical studies at the Eurostat site in Luxemburg. However, the micro-aggregation procedures chosen by Eurostat allow us in principle to apply the full set of micro-econometric techniques even with the aggregated data. The possibility of a

\footnotetext{
8 France had no questions on innovation obstacles, Portugal and the Netherlands had missing values for some innovation obstacles, Greece and Norway had too few observations, and the Belgian survey was actually the result of three regional surveys and therefore not considered homogeneous enough.
} 
micro-aggregation bias in the presence of nonlinear estimation techniques is an interesting topic in itself, but we shall not pursue it here.

Of particular importance is a survey question in which firms were asked to evaluate the importance of potential innovation obstacles. These obstacles can be categorized into four groups (see Appendix 2): factors relating to risk and finance, factors relating to knowledge-skill within the enterprise, factors measuring the knowledge-skill outside the enterprise, and finally regulation. The country heterogeneity in obstacle perception and the complementarity between these potential impediments are the focus of this paper.

Aggregating the obstacles in each group would be inconsistent with our assumption of obstaclespecific functions linking constraints to government actions. Therefore we have decided to analyze four specific obstacles, the most representative a priori of each group: lack of appropriate sources of finance, lack of skilled personnel, lack of opportunities of cooperation with other firms and technological institutions, and legislation, norms, regulations, standards, taxation (see Appendix 2). The respondents had to answer these questions on a Likert scale (one to five).

There may very well be a country specific response bias, which could for instance be due to differences across countries in survey methods or questionnaires. In order to control our estimates for such country effects in responding to the questionnaire, we have transformed the responses into binary responses, according to whether or not the response to each question was above or below the average country response (for all obstacles and industries), which was 1.89 in Ireland, 2.03 in Denmark, 2.10 in Germany and 1.94 in Italy.

The data have been cleaned for outliers, missing values and inconsistencies. In particular we dropped firms with less than 20 employees, with sales growth rates higher than $250 \%$ or lower than $-40 \%$ between 1990 and 1992, with R\&D/sales ratios higher than 50\%. We eliminate $17 \%$ of the original sample for Denmark, 30\% for Ireland, 36\% in Germany and 17\% in Italy.

\subsection{Complementarity Test - Specification}

To test the inequality constraints implied by complementarity, we need to get consistent estimates of the effects of obstacles on innovation. Recall from [2] that the innovation function at the industry level is determined by the states of obstacles perception as well as other exogenous industry and country specific effects. Recall further that we have assumed that the function is separable. We therefore specify the following innovation function for a particular industry

$$
I_{i j}=\sum_{l=0}^{2^{k}-1} \gamma_{l i} s_{l j}+\alpha_{i} \cdot Z_{i j}+\alpha_{i j} \cdot D_{j}+\varepsilon_{i j}
$$

where $I$ is a measure of innovation. There are a number of possible variables related to innovative activities in the CIS data set. We use the percentage in sales of innovative products as our innovation variable. In addition, we control for several exogenous factors that influence innovation, $Z_{i j}$. As exogenous shifters we use size dummies, a dummy for whether the firm belongs to a group, the R\&D per sales ratio, a dummy for continuous $R \& D$, and a dummy for whether the firm is engaged in cooperative $R \& D$. In line with our above framework, we control 
for industry and country specific exogenous variables, $\theta_{i j}$. We do so by specifying country specific fixed effects, $D_{j}$, and by estimating a separate regression for each industry. Summary statistics of all variables used in [4] are provided in Table 1.

Turning to the obstacles we define $s_{l i j}$ as a dummy variable corresponding to state $l$ in country $j$ and industry $i$. For convenience, we define the dummy variables by following the convention of binary algebra9. Note the in [4] there are 16 state dummies, which are allowed to vary across industries, but are constant across countries. As discussed above, this is in line with the idea that the complementarity structure is identical across countries for a given industry, and also a consequence of the separability assumption. Using this specification of the innovation function and the definition of the state dummies, we can write the inequality constraints for supermodularity as a set of restrictions on the coefficients on the state variables ${ }^{\mathbf{1 0}}$. Using [3] and [4], the four constraints for obstacles 1 and 2 to be complementary can be compactly written as (we drop the subscript $i$ for convenience),

$$
\gamma_{8+s}+\gamma_{4+s} \leq \gamma_{0+s}+\gamma_{12+s}, \text { where } s=0,1,2,3
$$

Similarly, the other complementarity conditions can be written as,

$$
\begin{aligned}
& \gamma_{8+s}+\gamma_{2+s} \leq \gamma_{0+s}+\gamma_{10+s}, \quad \text { where } s=0,1,4,5 \\
& \gamma_{8+s}+\gamma_{1+s} \leq \gamma_{0+s}+\gamma_{9+s}, \quad \text { where } \mathrm{s}=0,2,4,6 \\
& \gamma_{4+s}+\gamma_{2+s} \leq \gamma_{0+s}+\gamma_{6+s}, \quad \text { where } s=0,1,8,9 \\
& \gamma_{4+s}+\gamma_{1+s} \leq \gamma_{0+s}+\gamma_{5+s} \text {, where } s=0,2,8,10 \\
& \gamma_{2+s}+\gamma_{1+s} \leq \gamma_{0+s}+\gamma_{3+s} \text {, where } s=0,4,8,12
\end{aligned}
$$

Note that complementarity over the entire set will involve all 24 constraints to hold for a given industry. However, complementarity in innovation may also be present over a subset of the above constraints.

We are now ready to specify our test for supermodularity assuming that we have consistent estimates of the $\gamma_{l i}$ 's from [4]. As we mentioned above, it suffices to test obstacles in a pairwise fashion. For computational reasons, which will become apparent below, we are unable to test all the 24 inequality constraints simultaneously. We therefore proceed by testing complementarity for each pair of obstacles separately.

We propose to carry out two types of tests depending on what we choose as our null hypothesis. The first test takes (weak) supermodulatity as its null hypothesis, while the alternative is no supermodularity in the innovation function. In this case, the test for complementarity in the innovation function between obstacles 1 and 2 is given by,

\footnotetext{
${ }^{9}$ In other words, $s_{l 0}$ corresponds to state $0000, s_{l 1}$ to $0001, \ldots ., s_{l 15}$ to 1111.
} 


$$
\begin{array}{ll}
H_{0}:-\gamma_{0+s}+\gamma_{4+s}+\gamma_{8+s}-\gamma_{12+s} \leq 0, \ldots . s=0,1,2,3 & \text { [weak supermodularity] } \\
H_{1}:-\gamma_{0+s}+\gamma_{4+s}+\gamma_{8+s}-\gamma_{12+s}>0, \ldots . s=0,1,2,3 & \text { [no supermodularity] }
\end{array}
$$

The other 6 complementarity relationships are analogous. Intuitively, complementarity is rejected when the upper tail of the joint distribution of the parameter constraints corresponding to a pair of obstacles is sufficiently small. To compute this joint probability for the above test, we need to integrate a four-variate distribution function. More precisely, at the boundary the null hypothesis can be expressed as an equality constraint in the form $S \gamma=0$, where $S$ is a $4 x 2^{k}$ matrix, where $S$ is partitioned as $\left[S^{0}\left|S^{1}\right| S^{2} \mid S^{3}\right]$. Under the null hypothesis $(S \gamma=0)$ the joint restrictions are distributed as $v=S \hat{\gamma} \sim N\left(0, S \operatorname{cov}(\hat{\gamma}) S^{\prime}\right)$, where $\operatorname{cov}(\hat{\gamma})$ is the variance-covariance matrix of the estimated $\gamma$ coefficients. The p-value of rejecting the null hypothesis is given by the value of the upper tail distribution of a four-variate normal distribution $\int_{S^{0} \gamma s^{\prime} \gamma s^{2} \gamma s^{3} \gamma}^{\infty} \int^{\infty} \varphi(v) d v$. For instance, a value of the upper tail for this integral of 0.06 implies that there is a probability of error of $6 \%$ by rejecting the null of supermodularity for a pair of obstacles. In other words, large p-values imply acceptance of weak supermodularity.

The second test we propose is more conservative, and takes (strong) complementarity as the alternative. In this case, the test for complementarity in the innovation function between obstacles 1 and 2 is given by (again the other 6 complementarity relationships are analogous),

$$
\begin{array}{ll}
H_{0}:-\gamma_{0+s}+\gamma_{4+s}+\gamma_{8+s}-\gamma_{12+s} \geq 0, \ldots . . s=0,1,2,3 & \text { [no supermodularity] } \\
H_{1}:-\gamma_{0+s}+\gamma_{4+s}+\gamma_{8+s}-\gamma_{12+s}<0, \ldots . s=0,1,2,3 & \text { [strong supermodularity] }
\end{array}
$$

In this case, no complementarity is rejected when the lower tail of the joint distribution of the parameter constraints corresponding to a pair of obstacles is sufficiently small. The p-value of rejecting the null hypothesis is given by the value of the lower tail distribution of a four-variate normal distribution $\int_{-\infty}^{S^{0} \hat{\gamma}} \int_{-\infty}^{S^{1} \hat{\gamma}} \int_{-\infty}^{S^{2} \hat{\gamma}} \int_{-\infty}^{S^{3} \hat{\gamma}} \varphi(v) d v$. For instance, a value of the lower tail for this integral of 0.06 implies that there is a probability of error of $6 \%$ by accepting the alternative of supermodularity for a pair of obstacles. In other words, low p-values indicate evidence in favor of strong supermodularity.

It is clear that the two tests are just the complement of each other, since they integrate up to the same values of the constraints. However, the second test is more demanding in terms of finding supermodularity, since the null hypothesis is chosen as no supermodularity. We therefore report

\footnotetext{
10 It is worth mentioning that the above specification [4] can also be equivalently written in terms of obstacle dummies instead of state dummies. In this case, intuitively, the conditions for complementarity concern interaction effects between obstacles. Note that this is not equivalent to the cross-partials between those two obstacles, since the derivative w.r.t. a discrete variable is not defined.
} 
both tests below. To compute the test statistics we need to compute the four-variate integrals, which is done by using the GHK simulator (see Mariano et al, 2000). ${ }^{\mathbf{1 1}}$

Before we report our test results, we need to return to the estimation of [4]. Recall that our supermodularity test is based on consistent estimates of the $\gamma_{l i}$ 's.

\subsection{Econometric Issues and Estimation}

An important consideration is to obtain consistent and efficient estimates of the $\gamma_{l i}$ 's. A significant problem might arise due to the fact that we observe innovation activity by a particular firm only if this firm in fact innovates. Many firms in our sample do not innovate at all, i.e. we have that $I_{i j}=0$, which may give rise to serious censoring.

Besides the econometric problem of censoring, which has to be handled properly to lead to consistent estimates of innovation, we may also be interested to test the hypothesis of complementarity in whether firms do innovate at all. As we mentioned above, there are actually two separate effects of obstacles on innovation activities. The first one is on the intensity of innovation, conditionally on innovating at all. Second, obstacles might prevent a firm from doing any innovation at all. In principle, a change in the obstacles to innovation will have an impact on both effects: the probability of innovating and the intensity of innovating.

In order to capture the second effect of obstacles on innovation and to correct for censoring, we specify a probit model for the probability of innovating (suppressing firm subscripts again):

$$
P I_{i j}=\sum_{l=0}^{2^{k}-1} \lambda_{l i} s_{l i j}+\beta_{i} \cdot Z_{i j}+\beta_{i j} \cdot D_{j}+\mu_{i j}
$$

where $P I_{i j}$ is the latent variable corresponding to the probability of innovating, $Z_{i j}$ are exogenous variables (size and group dummies in this case), and $s_{l i j}$ are the states of obstacle perception defined above. Innovating firms have positive values for $P I_{i j}$, non-innovating firms have negative values. A firm is considered as innovative if it reports a positive share in sales of innovative products. ${ }^{12}$ The error terms $\varepsilon_{i j}$ and $\mu_{i j}$ are assumed to be jointly normally distributed with mean zero and variance-covariance matrix $\Sigma$, with $\sigma_{11}=1, \sigma_{22}=\sigma_{2}^{2}, \sigma_{12}=\rho \sigma_{2} .{ }^{13}$

Consistent estimates of the parameters in [4] and [5] are obtained by estimating a generalized tobit model with maximum likelihood. We maximize the likelihood of observing the binary data on whether a firm innovates or not, and on the intensity if it is innovative. In order to have $\mu_{i j}$ vary between $-\infty$ to $+\infty$, we transform $I_{i j}$, bounded between 0 and 1 , to $\ln \left(I_{i j} /\left(1-I_{i j}\right)\right)$ and add the corresponding Jacobian to the likelihood function, yielding:

\footnotetext{
${ }^{11}$ We thank Donis Bolduc for sharing the Gauss programming of the GHK simulator.

${ }^{12}$ Few firms declare to be innovative in processes and not in products. By focusing on shares in sales of innovative products, we actually capture process innovations as well.

${ }^{13} \sigma_{11}=1$ for reasons of identification.
} 


$$
\begin{aligned}
\ln L & =\sum_{0} \ln \left[1-\Phi\left(x_{1} \beta_{1}\right)\right]+\sum_{1} \ln \Phi\left(\frac{x_{1} \beta_{1}+\rho / \sigma_{2}\left[\ln (I /(1-I))-x_{2} \beta_{2}\right]}{\sqrt{1-\rho^{2}}}\right) \\
& \left.+\sum_{1} \ln \left(1 / \sigma_{2}\right)[I(1-I))\right]^{-1} \varphi\left[\left(\ln (I /(1-I))-x_{2} \beta_{2}\right) / \sigma_{2}\right]
\end{aligned}
$$

where for notational convenience we drop the $i$ and $j$ subscripts, denote the regressors and parameters appearing in [4] as $x_{2}$ and $\beta_{2}$ respectively, and those in [5] as $x_{1}$ and $\beta_{1}$. The index 0 under the summation sign refers to non-innovators and the index 1 to innovators. $\Phi$ denotes the standard normal distribution and $\varphi$ the standard normal density.

The constraints and hypothesis test for complementarity in becoming an innovator are analogous to the previous sub-section except that the $\gamma_{l}$ 's are replaced by the corresponding $\lambda_{l}$ 's.

\section{Empirical Results}

Before we turn to the econometric evidence, we present some descriptive evidence in form of simple count statistics. The idea is to infer something about complementarity by looking at occurrences. For instance if obstacle one occurs more often together with obstacle two, rather than separately, we might conclude that complementarity between the two obstacles exist. Table 2 shows the frequency of occurrences of our 16 states in the full sample of all observations in the four countries, as well as in the sub-sample of innovating firms. The occurrences are classified in the order of binary arithmetic.

Looking at Table 2, it is clear that the most frequent responses are the two extremes; zero everywhere and one everywhere, as well as lack of appropriate sources of finance and zero for the other obstacles. It appears that there is some evidence of complementarity in this data. In terms of pairwise complementarity, there are a large number of possible counts to consider. For example, in the food industry, obstacle 3 (external knowledge) and obstacle 4 (regulation) are more often perceived similarly (strong if 1 , weak if 0 ) than differently, regardless of how the other two obstacles are perceived: the occurrence of (0000) plus (0011) is more frequent than (0001) plus (0010), etc. This holds for both data sets, i.e. ALL FIRMS (top of Table 2) as well as INNOVATORS (bottom of Table 2). A similar result applies to obstacle 1 (finance) and obstacle 2 (personnel). We therefore have some descriptive evidence of pairwise complementarity.

There is however, also evidence of lack of complementarity. For example, in the metal industry obstacles 3 and 4 are not complementary as indicated by occurrences: the frequency of (0100) plus (0111) is smaller than (0101) plus (0110) for INNOVATORS (bottom of Table 2). Interestingly, the complementarity is present if one considers ALL FIRMS, which implies that the censoring problem discussed above may be important in determining complementarity.

In sum, it appears that the descriptive evidence regarding supermodularity is mixed. Of course, looking at counts can only be considered suggestive and yields a very large number of possible computations. We now turn to a more systematic approach, which further controls for other exogenous factors. 


\section{Econometric Results}

Consistent estimates of the parameters in [4] and [5] for each industry are obtained by estimating a generalized tobit model with maximum likelihood. We use the estimates of $\hat{\gamma}_{l}$ and $\hat{\lambda}_{l}$ to calculate the tests of complementarity described above for both the probability of becoming an innovator (through $\hat{\lambda}_{l}$ ) as well as the intensity of innovation (through $\hat{\gamma}_{l}$ ). ${ }^{\mathbf{1 4}}$

Table 3 presents the p-values of the first supermodularity test discussed above, i.e. where we specify weak supermodularity as the null hypothesis. Recall that the p-values indicate the probability of error by rejecting the null of weak supermodularity for a pair of obstacles. Table 3 presents p-values for each pair of obstacles for every industry and for both the probability to innovate and for the intensity of innovation. For instance, the hypothesis that lack of finance (obstacle 1) and lack of internal human capital (obstacle 2) are complementary in affecting the probability of innovating in the food industry cannot be rejected at any reasonable level of significance ( $p$-value of .956). In fact, this finding holds for each pair of obstacles in all industries. In addition, we cannot reject weak supermodularity neither for the intensity of innovation nor for the probability of becoming an innovator. We therefore conclude that our test of weak supermodularity unanimously accepts the hypothesis of supermodularity in the innovation process.

As we indicated above, the second test is more demanding in terms of finding support for the supermodularity hypothesis. Table 4 presents the p-values of the strong supermodularity test, i.e. where we specify strong supermodularity as the alternative hypothesis. Recall that the p-values indicate the probability of error by rejecting the null of no supermodularity. For instance, the hypothesis that obstacle 1 (finance) and obstacle 2 (internal human capital) are not complementary in terms of the probability of innovating in the food industry can be rejected at a $5 \%$ significance level (p-value of .044) ${ }^{15}$.

The p-values in Table 4 indicate that the hypothesis of no supermodularity in innovation policy cannot be rejected for all obstacles and all industries. However, there are a large number of pairwise complementarities that are statistically significant. This is true for the probability of being an innovator as well as for the intensity of innovation. It is also clear, that not all the obstacles are complementary in all industries. In other words, not surprisingly we do not have full complementarities across all industries. However, several industries display a high degree of supermodularity in the innovation process. For instance, the food industry, the wood industry, the machinery and equipment industry, and the vehicle industry all exhibit full complementarities in the intensity of innovation at a $10 \%$ level.

\footnotetext{
${ }^{14}$ We have tested the joint significance of the coefficients relating to the obstacles to innovation. A Wald test revealed that for most industries the obstacles are jointly significant at a $10 \%$ level. The only exception for [4] is the food industry, which is only significant at the $16 \%$ level. The results for [5] are somewhat less significant, even though most are still significant. The exceptions here are food (20\% significance level), textile (30\%) non-metallic $(88 \%)$ and vehicle $(33 \%)$.

15 Note that as expected the values in Tables 3 and 4 are just the complements of each other. For clarity, we present both tables.
} 
By contrast, the probability of innovating is much less complementary. In fact, there is no industry in which full complementarity exists at the $10 \%$ level. Nevertheless, there is no single obstacle that is not complementary to at least one other obstacle. The only exception is the chemical industry, where obstacle 3 is not complementary to any other obstacle.

We therefore find that all industries display a considerable amount of complementarity, with the complementary being more pronounced in the intensity of innovation than in the probability of becoming an innovator. This indicates that these two innovation processes, i.e. the intensity of innovation vs. the probability of becoming an innovator are subject to different constraints.

Table 3 also shows that all obstacles are complementarity in several industries. In other words, the four obstacles (finance, internal human capital, external knowledge, and regulation) are interrelated in a significant subset of the industries, which implies a trade off at the country level in terms of policy. The highest number of significant complementary relationships for innovation is estimated between obstacles 2 and 3 (internal human capital and external knowledge) and obstacles 2 and 4 (internal human capital and regulations), which are both significant at the $10 \%$ level in 10 out of the 11 industries. The former reflects the well-known absorption hypothesis, according to which internal and external knowledge reinforce each other. The latter indicates that lack of human capital is more constraining in regulated firms. Considering the probability of becoming an innovator, we find the highest number of complementary relationships between finance and internal human capital with 9 out of 11 industries displaying significant complementarity at the $10 \%$ level. The lack of external capital is exacerbated by a lack of skilled personnel.

\section{Conclusion}

This paper develops a framework for testing whether complementarities in innovation policy exist. We specify and estimate an innovation function that allows us to test for supermodularity in innovation policy. We also differentiate between two separate effects: the first one is on the intensity of innovation, conditional that a firm does any innovation at all, and secondly, whether a firm does any innovation or not.

We find that industries display a considerable amount of complementarity, with some industries being complementary across all obstacles. Generally, complementary in the intensity of innovation appears to be more pronounced than in the probability of becoming an innovator. This indicates that these two innovation processes, i.e. the intensity of innovation vs. the probability of becoming an innovator are subject to different constraints. This also implies that policies to remove obstacles to innovation may result in rather different effects, depending on whether they are designed to stimulate innovation by incumbents (i.e. the intensity of innovation, conditional on being an innovator) or to stimulate entry (i.e. increase the probability of becoming an innovator).

In terms of obstacles we find that the lack of internal human capital (skilled personal) is complementary with all the other obstacles in almost all industries. This is true for both the 
intensity of innovators as well as new innovators. It appears that internal human capital is key, insofar that it is complementary to all the other factors that might hempen innovation activities.

In terms of innovation policy this finding of human capital complementarity suggests that measures directed at removing barriers to innovation may be more effective if those measures are also explicitly directed at increasing the level of internal human capital. 
Table 1: Summary Statistics

CIS I, micro-aggregated data, 1992 (sample mean)

\begin{tabular}{|c|c|c|c|c|c|c|c|c|c|c|c|}
\hline Variable & FOOD & TEXT. & WOOD & CHEM. & PLAST. & N.-MET & METAL & $M \& E$ & ELEC. & VEHIC. & NEC \\
\hline $\begin{array}{l}\text { Percentage of } \\
\text { innovators }\end{array}$ & 0.258 & 0.153 & 0.228 & 0.533 & 0.446 & 0.249 & 0.298 & 0.532 & 0.531 & 0.442 & 0.257 \\
\hline $\begin{array}{l}\% \text { in sales of innovative } \\
\text { products for innovators }\end{array}$ & 0.349 & 0.442 & 0.378 & 0.341 & 0.372 & 0.367 & 0.373 & 0.485 & 0.467 & 0.476 & 0.462 \\
\hline $\begin{array}{l}\text { Dummy for 20-49 } \\
\text { employees }\end{array}$ & 0.561 & 0.656 & 0.628 & 0.376 & 0.566 & 0.593 & 0.625 & 0.498 & 0.487 & 0.461 & 0.699 \\
\hline $\begin{array}{l}\text { Dummy for 50-99 } \\
\text { employees }\end{array}$ & 0.171 & 0.202 & 0.198 & 0.196 & 0.227 & 0.202 & 0.189 & 0.224 & 0.210 & 0.190 & 0.178 \\
\hline $\begin{array}{l}\text { Dummy for } 100-249 \\
\text { employees }\end{array}$ & 0.155 & 0.101 & 0.117 & 0.209 & 0.133 & 0.120 & 0.121 & 0.151 & 0.154 & 0.161 & 0.087 \\
\hline $\begin{array}{l}\text { Dummy for 250-499 } \\
\text { employees }\end{array}$ & 0.063 & 0.028 & 0.027 & 0.098 & 0.044 & 0.047 & 0.037 & 0.059 & 0.071 & 0.079 & 0.023 \\
\hline $\begin{array}{l}\text { Dummy for } 500-999 \\
\text { employees }\end{array}$ & 0.030 & 0.009 & 0.017 & 0.058 & 0.020 & 0.020 & 0.017 & 0.032 & 0.040 & 0.042 & 0.006 \\
\hline $\begin{array}{l}\text { Dummy for }>999 \\
\text { employees }\end{array}$ & 0.020 & 0.004 & 0.013 & 0.064 & 0.010 & 0.017 & 0.012 & 0.037 & 0.039 & 0.067 & 0.006 \\
\hline $\begin{array}{l}\text { Dummy for being } \\
\text { part of a group }\end{array}$ & 0.248 & 0.101 & 0.201 & 0.515 & 0.270 & 0.233 & 0.203 & 0.270 & 0.323 & 0.277 & 0.108 \\
\hline Export/sales ratio & 0.129 & 0.206 & 0.093 & 0.215 & 0.228 & 0.163 & 0.151 & 0.342 & 0.229 & 0.244 & 0.244 \\
\hline Number of employees & 151 & 72 & 94 & 484 & 158 & 147 & 131 & 231 & 291 & 1203 & 73 \\
\hline $\begin{array}{l}\mathrm{R} \& \mathrm{D} / \mathrm{sales} \text { ratio for } \\
\text { innovators }\end{array}$ & 0.011 & 0.014 & 0.011 & 0.032 & 0.017 & 0.020 & 0.019 & 0.028 & 0.047 & 0.030 & 0.016 \\
\hline $\begin{array}{l}\% \text { of innovators doing } \\
\text { R\&D continuously }\end{array}$ & 0.447 & 0.427 & 0.289 & 0.768 & 0.527 & 0.535 & 0.432 & 0.656 & 0.697 & 0.609 & 0.403 \\
\hline $\begin{array}{l}\% \text { of innovators doing } \\
\text { cooperative R\&D }\end{array}$ & 0.168 & 0.052 & 0.081 & 0.314 & 0.119 & 0.132 & 0.114 & 0.167 & 0.245 & 0.262 & 0.052 \\
\hline $\begin{array}{l}\text { Number of } \\
\text { observations }\end{array}$ & 1541 & 4540 & 1899 & 1059 & 963 & 1433 & 3372 & 2930 & 1964 & 788 & 1578 \\
\hline
\end{tabular}


Table 2: Obstacle Occurrences

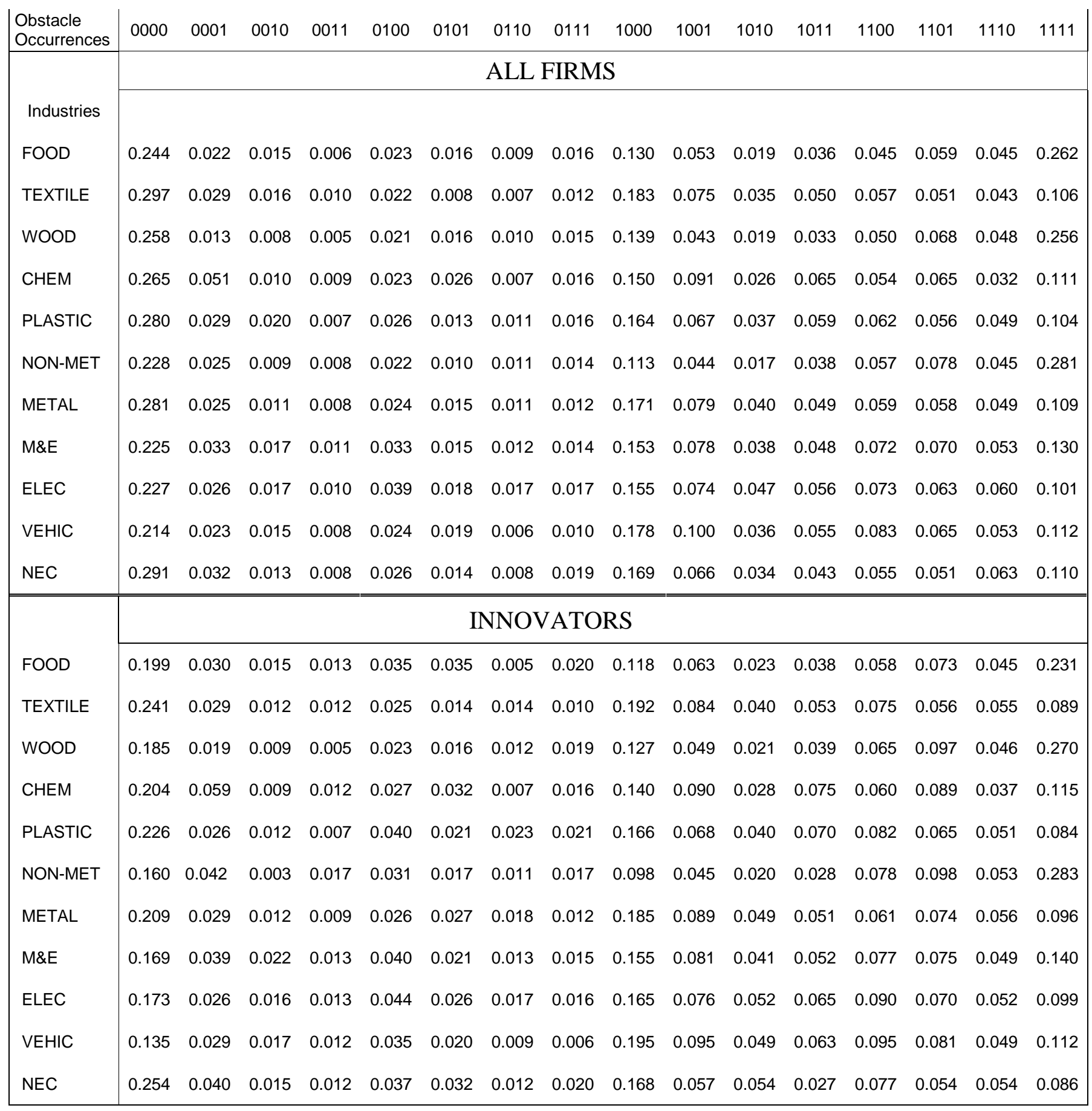

Obstacle Definition: 1= Lack of appropriate sources of finance, 2= Lack of skilled personnel, 3= Lack of opportunities for cooperation with other firms and technological institutions, 4= Legislation, norms, regulations, standards, taxation. 
Table 3: Test of Complementarity in Innovation Policy p-values of weak supermodularity tests (generalized tobit)

\begin{tabular}{|c|c|c|c|c|c|c|c|c|c|c|c|c|}
\hline \multirow[b]{2}{*}{ Pairs of obstacles } & \multicolumn{6}{|c|}{ Probability to innovate } & \multicolumn{6}{|c|}{ Amount of innovation } \\
\hline & $1-2$ & $1-3$ & $1-4$ & $2-3$ & $2-4$ & $3-4$ & $1-2$ & $1-3$ & $1-4$ & $2-3$ & $2-4$ & $3-4$ \\
\hline \multicolumn{13}{|l|}{ Industries } \\
\hline FOOD & 0.956 & 0.984 & 0.815 & 0.612 & 0.852 & 0.966 & 0.949 & 0.986 & 0.912 & 0.993 & 0.983 & 0.998 \\
\hline TEXTILE & 0.950 & 0.981 & 0.953 & 0.942 & 0.787 & 0.912 & 0.826 & 0.978 & 0.939 & 0.998 & 0.975 & 0.998 \\
\hline WOOD & 0.961 & 0.842 & 0.990 & 0.849 & 0.932 & 0.975 & 0.968 & 0.990 & 0.930 & 0.908 & 0.993 & 0.999 \\
\hline CHEM & 0.996 & 0.899 & 0.989 & 0.616 & 0.923 & 0.845 & 0.929 & 0.879 & 0.992 & 0.826 & 0.951 & 0.973 \\
\hline PLASTIC & 0.759 & 0.937 & 0.832 & 0.911 & 0.844 & 0.923 & 0.732 & 0.996 & 0.681 & 0.998 & 0.974 & 0.947 \\
\hline NON-MET & 0.992 & 0.891 & 0.892 & 0.961 & 0.927 & 0.951 & 0.893 & 0.994 & 0.887 & 0.998 & 0.925 & 0.991 \\
\hline METAL & 0.767 & 0.945 & 0.847 & 0.943 & 0.966 & 0.690 & 0.908 & 0.897 & 0.971 & 0.946 & 0.951 & 0.477 \\
\hline$M \& E$ & 0.971 & 0.996 & 0.965 & 0.498 & 0.979 & 0.961 & 0.977 & 0.999 & 0.999 & 0.997 & 0.998 & 0.999 \\
\hline ELEC & 0.913 & 0.986 & 0.876 & 0.471 & 0.906 & 0.999 & 0.996 & 0.885 & 0.944 & 0.942 & 0.994 & 0.999 \\
\hline VEHIC & 0.990 & 0.943 & 0.977 & 0.562 & 0.956 & 0.935 & 0.996 & 0.900 & 0.981 & 0.995 & 0.939 & 0.995 \\
\hline NEC & 0.932 & 0.930 & 0.917 & 0.819 & 0.995 & 0.818 & 0.996 & 0.972 & 0.949 & 0.994 & 0.792 & 0.866 \\
\hline
\end{tabular}

Obstacle Definition: 1= Lack of appropriate sources of finance, $2=$ Lack of skilled personnel, $3=$ Lack of opportunities for cooperation with other firms and technological institutions, $4=$ Legislation, norms, regulations, standards, taxation. 
table 4: Test of Complementarity in Innovation Policy

p-values of strong supermodularity tests (generalized tobit)

\begin{tabular}{|c|c|c|c|c|c|c|c|c|c|c|c|c|}
\hline \multirow[b]{2}{*}{ Pairs of obstacles } & \multicolumn{6}{|c|}{ Probability to innovate } & \multicolumn{6}{|c|}{ Amount of innovation } \\
\hline & $1-2$ & $1-3$ & $1-4$ & $2-3$ & $2-4$ & $3-4$ & $1-2$ & $1-3$ & $1-4$ & $2-3$ & $2-4$ & $3-4$ \\
\hline \multicolumn{13}{|l|}{ Industries } \\
\hline FOOD & 0.044 & 0.016 & 0.185 & 0.388 & 0.148 & 0.034 & 0.051 & 0.014 & 0.088 & 0.007 & 0.017 & 0.002 \\
\hline TEXTILE & 0.050 & 0.019 & 0.047 & 0.048 & 0.213 & 0.088 & 0.174 & 0.022 & 0.061 & 0.002 & 0.025 & 0.002 \\
\hline WOOD & 0.039 & 0.048 & 0.010 & 0.151 & 0.068 & 0.025 & 0.032 & 0.010 & 0.070 & 0.092 & 0.007 & 0.001 \\
\hline CHEM & 0.004 & 0.101 & 0.011 & 0.384 & 0.077 & 0.155 & 0.071 & 0.121 & 0.008 & 0.174 & 0.049 & 0.027 \\
\hline PLASTIC & 0.241 & 0.063 & 0.168 & 0.089 & 0.156 & 0.077 & 0.268 & 0.004 & 0.319 & 0.002 & 0.026 & 0.053 \\
\hline NON-MET & 0.008 & 0.109 & 0.108 & 0.039 & 0.073 & 0.049 & 0.107 & 0.006 & 0.113 & 0.002 & 0.075 & 0.009 \\
\hline METAL & 0.233 & 0.055 & 0.153 & 0.057 & 0.034 & 0.310 & 0.092 & 0.103 & 0.029 & 0.054 & 0.049 & 0.523 \\
\hline M\&E & 0.029 & 0.004 & 0.035 & 0.502 & 0.021 & 0.039 & 0.023 & 0.001 & 0.001 & 0.003 & 0.002 & 0.001 \\
\hline ELEC & 0.087 & 0.014 & 0.124 & 0.529 & 0.094 & 0.001 & 0.004 & 0.115 & 0.056 & 0.058 & 0.006 & 0.001 \\
\hline VEHIC & 0.010 & 0.057 & 0.023 & 0.438 & 0.044 & 0.065 & 0.004 & 0.100 & 0.019 & 0.005 & 0.061 & 0.005 \\
\hline NEC & 0.068 & 0.070 & 0.083 & 0.181 & 0.005 & 0.182 & 0.004 & 0.028 & 0.051 & 0.006 & 0.208 & 0.134 \\
\hline
\end{tabular}

Obstacle Definition: 1= Lack of appropriate sources of finance, 2= Lack of skilled personnel, $3=$ Lack of opportunities for cooperation with other firms and technological institutions, $4=$ Legislation, norms, regulations, standards, taxation. 


\title{
Appendix 1
}

\author{
Industry Definitions
}

\begin{tabular}{|c|c|c|}
\hline Industry & NACE code & Description of Industry \\
\hline FOOD & $15-16$ & food, beverages and tobacco \\
\hline TEXTILE & $17-19$ & $\begin{array}{l}\text { textiles, wearing apparel, dressing and dyeing of fur, } \\
\text { tannings, and dressing of leather, luggage, handbags, saddlery, } \\
\text { harness and footwear }\end{array}$ \\
\hline WOOD & $20-22$ & $\begin{array}{l}\text { wood and products of wood and cork, except furniture, } \\
\text { straw and plaiting materials, pulp, paper, and paper products, } \\
\text { publishing, printing, and reproduction of recorded media }\end{array}$ \\
\hline CHEM & $23-24$ & $\begin{array}{l}\text { refined petroleum products and nuclear fuel, chemicals and } \\
\text { chemical products }\end{array}$ \\
\hline PLASTIC & 25 & rubber and plastic products \\
\hline NON-MET & 26 & other non-metallic mineral products \\
\hline METAL & $27-28$ & $\begin{array}{l}\text { basic metals, fabricated metal products, except machinery } \\
\text { and equipment }\end{array}$ \\
\hline M\&E & 29 & machinery and equipment \\
\hline ELEC & $30-33$ & $\begin{array}{l}\text { office machinery and computers, electrical machinery and } \\
\text { apparatus, radio, television and communication equipment and } \\
\text { apparatus, medical, precision and optical instruments, watches and } \\
\text { clocks. }\end{array}$ \\
\hline VEHIC & $34-35$ & $\begin{array}{l}\text { motor vehicles, trailers, semi-trailers, and other transport } \\
\text { equipment }\end{array}$ \\
\hline NEC & 36 & furniture \\
\hline
\end{tabular}




\title{
Appendix 2
}

\author{
Obstacles to innovation ${ }^{*}$
}

Category 1: Risk and finance

Excessive perceived risk

Lack of appropriate sources of finance

Innovation costs too high

Pay-off period of innovation too long

Category 2: Knowledge-skill within enterprise

Enterprises's innovation potential too small

Lack of skilled personnel

Lack of information on technologies

Lack of information on markets

Innovation costs hard to control

Resistance of change in the enterprise

Category 3: Knowledge-skill outside the enterprise

Deficiencies in the availability of external technical services

Lack of opportunities for cooperation with other firms and technological institutions Lack of technological opportunities

No need to innovate due to earlier innovations

Category 4: Regulations

Innovation too easy to copy

Legislation, norms, regulations, standards, taxation

Lack of customer responsiveness to new products and processes

Uncertainty in timing of innovation

\footnotetext{
* The representative obstacles used in the analysis of this paper are in bold.
} 


\section{References}

Arora, A. (1996), "Testing for Complementarities in Reduced-Form Regressions: A Note", Economics Letters, 50, 51-55.

Athey, S, and S. Stern (1998), "An Empirical Framework for Testing Theories About Complementarity in Organizational Design," NBER working paper.

Dosi, G. (1988), "Sources, procedures and microeconomic effects of innovation", Journal of Economic Literature, 36, 1126-71.

Eisner, R., S. H. Albert and M. Sullivan (1984), "The New Incremental Tax Credit for R-D: Incentive or Disincentive", National Tax Journal, 37, 171-183.

Ichniowski, C., K. Shaw, and G. Prennushi, (1997) "The Effect of Human Resource management Practices on Productivity: A Study of Steel Finishing Lines," American Economic Review, Vol.87, No.3, 291-313.

Levin, R., A. Klevorick, R. Nelson and S. Winter (1988), "Appropriating the Returns from Industrial Research and Development", Brookings Papers on Economic Activity, 3, 783-832.

Mariano, R., T. Schuermann, and M. Weeks (2000), Simulation-based Inference in Econometrics, Cambridge University Press, Cambridge.

Milgrom, P and J. Roberts (1990), "The Economics of Modern Manufacturing, Technology, Strategy and Organization“, American Economic Review, 80, 511-528.

Milgrom, P. and J. Roberts (1994), "Complementarities and Systems: Understanding Japanese Economic Organization“, Estudios Economicos, 9(1), 3-42.

Milgrom, P. and C. Shannon (1994), "Monotone Comparative Statics", Econometrica, 62(1), 157-180.

Miravete, E. and J. Pernìas (2000), "Innovation Complementarities and Scale of Production“, mimeo.

North, D.C. (1994), "Economic Performance through Time", American Economic Review, vol. 84, pp. 359368.

Topkis, D.M., (1978), "Minimizing a Submodular Function on a Lattice", Operations Research, vol. 26, pp.305-321.

Topkis, D.M., (1998), Supermodularity and Complementarity, Princeton University Press, Princeton.

Vives, X., (1990), "Nash Equilibrium with Strategic Complementarities", Journal of Mathematical Economics, 19:305-321. 


\section{Liste des publications au CIRANO*}

\section{Cahiers CIRANO / CIRANO Papers (ISSN 1198-8169)}

99c-1 Les Expos, l'OSM, les universités, les hôpitaux : Le coût d'un déficit de 400000 emplois au Québec — Expos, Montréal Symphony Orchestra, Universities, Hospitals: The Cost of a 400,000-Job Shortfall in Québec / Marcel Boyer

Série Scientifique / Scientific Series (ISSN 1198-8177)

2001s-27 Bankruptcy Cost, Financial Structure and Technological Flexibility Choices / Marcel Boyer, Armel Jacques et Michel Moreaux

2001s-26 Inflation as a Strategic Response / M. Martin Boyer et Pierre Thomas Léger

2001s-25 Simulation-Based Finite-Sample Tests for Heteroskedasticity and ARCH Effects / Jean-Marie Dufour, Lynda Khalaf, Jean-Thomas Bernard et Ian Genest

2001s-24 The Role of Organizational Commitment and Citizenship Behaviors in Understanding Relations between Human Resources Practices and Turnover Intentions of IT Personnel / Guy Paré, Michel Tremblay et Patrick Lalonde

2001s-23 A Resource-Based Analysis of Outsourcing: Evidence from Case Studies / Vital Roy et Benoit Aubert

2001s-22 Short and Long Memory in Equilibrium Interest Rate Dynamics / Jin-Chuan Duan et Kris Jacobs

2001s-21 Unemployment Insurance and Subsequent Job Duration: Job Matching vs Unobserved Heterogeneity / Christian Belzil

2001s-20 Estimating the Intergenerational Education Correlation from a Dynamic Programming Model / Christian Belzil et Jörgen Hansen

2001s-19 The Bootstrap of the Mean for Dependent Heterogeneous Arrays / Sílvia Gonçalves et Halbert White

2001s-18 Perspectives on IT Outsourcing Success: Covariance Structure Modelling of a Survey of Outsourcing in Australia / Anne C. Rouse, Brian Corbitt et Benoit A. Aubert

2001s-17 A Theory of Environmental Risk Disclosure / Bernard Sinclair-Desgagné et Estelle Gozlan

2001s-16 Marriage Market, Divorce Legislation and Household Labor Supply / Pierre-André Chiappori, Bernard Fortin et Guy Lacroix

2001s-15 Properties of Estimates of Daily GARCH Parameters Based on Intra-Day Observations / John W. Galbraith et Victoria Zinde-Walsh

2001s-14 A Ricardian Model of the Tragedy of the Commons / Pierre Lasserre et Antoine Soubeyran

2001s-13 Carbon Credits for Forests and Forest Products / Robert D. Cairns et Pierre Lasserre

\footnotetext{
* Consultez la liste complète des publications du CIRANO et les publications elles-mêmes sur notre site Internet :
} 